07

\title{
„Зародышевые“ трещины на поверхности кристалла кремния
}

\author{
(С) В.И. Веттегрень, А.Г. Кадомцев, И.П. Щербаков, Р.И. Мамалимов, Г.А. Оганесян \\ Физико-технический институт им. А.Ф. Иофрфе РАН, \\ Санкт-Петербург, Россия \\ E-mail: Victor.Vettegren@mail.ioffe.ru
}

Поступила в Редакцию 24 мая 2021 г.

В окончательной редакции 24 мая 2021 г.

Принята к публикации 25 мая 2021 г.

\begin{abstract}
Методами интерференционной профилометрии белого света и фотолюминесцентной спектроскопии (PL) исследована поверхность (100) кристалла кремния после резки заготовки алмазным диском и последующей полировки. Обнаружено, что она покрыта „бороздками“. Их длина $-10-40 \mu \mathrm{m}$, а глубина квантована имеет 4 преимущественных значения - 1, 2.6, 3.6 и $4.5 \mathrm{~nm}$. В спектрах PL поверхности наблюдали 4 полосы - 1.63, 1.62, 1.68 и $2.25 \mathrm{eV}$, которые возникают из-за конфайнмента, т. е. увеличения ширины запрещенной зоны и нарушением закона сохранения импульса в нанокристаллах. По энергии максимумов этих полос определены размеры нанокристалов - 2, 2.3, 3 и $4 \mathrm{~nm}$. При резке кремния или удара по нейму бойком наблюдали сигналы фрактолюминесценции (FL), содержавшие по 4 максимума. Сигналы образуются при прорыве дислокациями барьеров, возникающих в местах пересечения плоскостей скольжения и образовании „зародышевых“ трещин. По скорости роста интенсивности максимумов, определены размеры трещин: 1.9, 3, 3.2 и $6 \mathrm{~nm}$. Совпадение значений глубин бороздок, размеров кристаллов и „зародышевых“ трещин позволило сделать вывод, что бороздки представляют собой „зародышевые“ трещины.
\end{abstract}

Ключевые слова: интерференционная профилометрия, фотолюминесценция, фрактолюминесценция, кремний, „зародышевые“ трещины, разрушение.

DOI: $10.21883 /$ FTT.2021.10.51410.122

\section{1. Введение}

Известно, что разрушение кристаллов под влиянием механических напряжений начинается с накопления и объединения трещин [1-4]. Самые мелкие из них „зародышевые“, по-видимому, образуются при прорыве дислокациями барьеров, препятствующих их движению по плоскостям скольжения [5,6].

В работах [7-10] для регистрации „зародышевых“ трещин был использован метод фрактолюминесценции (FL) с временным разрешением 2 ns. При разрушении кристаллической решетки образуются возбужденные свободные радикалы. Через несколько ns электроны с возбужденных орбиталей в этих радикалах переходят на основные. При этом выделяется энергия в виде FL [11]. Анализ формы и кинетики накопления сигналов показал, что они возникают при образовании ,зародышевых“ трещин [7-10].

Представляло интерес зарегистрировать такие трещины другими методами. В данной работе для этой цели были использованы методы интерференционной оптической профилометрии белого света и фотолюминесценции (PL).

\section{2. Объект и методы исследования}

Пластины кремния (100) получены путем резки заготовки алмазным диском и последующей полировки.

Профиль поверхности образцов получен на интерференционном оптическом профилометре белого света
Zygo New View 6000 в УНУ „Физика, химия, и механика кристаллов и тонких пленок“ (ИПМаш РАН, Санкт-Петербург). Профилометр позволяет исследовать профиль поверхности с погрешностью по вертикали $\leq 0.8 \mathrm{~nm}$ и по горизонтали - меньше $1 \mu \mathrm{m}$.

Спектры PL возбуждались ультрафиолетовым светодиодом LED UVTOP280TO39HS (длина волны излучения $285 \mathrm{~nm}$ ) и записывались на оптоволоконном спектрометре с ультранизким рассеянием света фирмы AVANTES - AvaSpec-ULSi2048L-USB2 OEM. Луч светодиода падал на поверхность образца под углом $45^{\circ}$ к ней. Размер светового пятна на поверхности составлял $2 \mathrm{~mm}$.

Для исследования динамики образования „зародышевых“ трещин при разрушении кремния использовали метод FL. FL возбуждалась при резании кремния или при ударе по стальному бойку, установленному на поверхности образца. Возникающее излучение при помощи кварцевой линзы фокусировали на поверхность катода фотоэлектронного умножителя РЕМ 136. Сигнал с его выхода подавался на вход аналогово-цифрового преобразователя ADS - 3112 фирмы „ACTACOM“. Напряжение на его выходе через каждые 2 ns записывалось в память компьютера.

\section{3. Дефекты на поверхности образца кремния}

На рис. 1 показана поверхность образца кремния после резки заготовки алмазным диском и последующей 


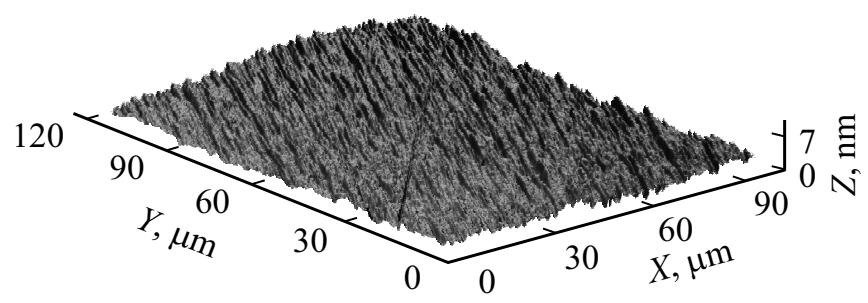

Рис. 1. Поверхность (100) кристалла кремния после резки и полировки.

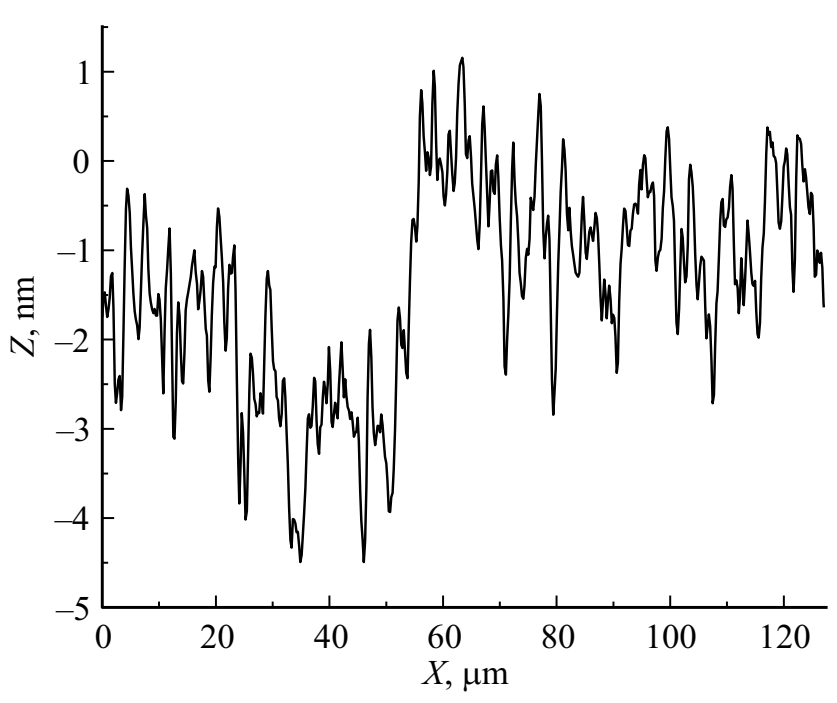

Рис. 2. Сечение профиля поверхности параллельно оси $X$ на рис. 1.

полировки. Видно, что она содержит множество дефектов — „канавок“, длина которых заключена в пределах $(10-30) \mu \mathrm{m}$.

На рис. 2 показан профиль одного из произвольно выбранных сечений изображения поверхности параллельно оси $X$. Его рассмотрение показывает, что бороздки имеют разную глубину. Анализ таких профилей показал, что распределение канавок по глубине представляет собой сумму 4 максимумов гауссовой формы (рис. 3). Больше всего канавок имело глубину $(2.6 \pm 0.1) \mathrm{nm}$

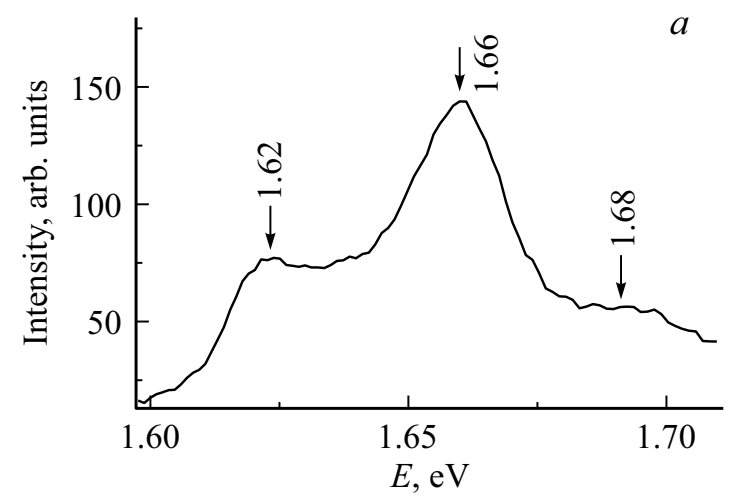

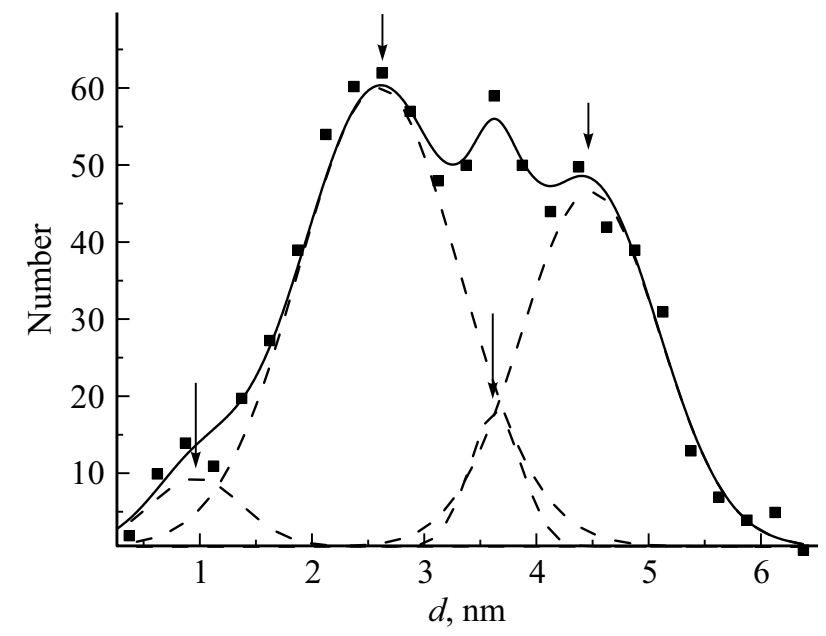

Рис. 3. Распределение глубин $d$ впадин в произвольно выбранном сечении профиля поверхности. Пунктир - составные распределения; сплошная линия - сумма распределений.

и $(4.5 \pm 0.1) \mathrm{nm}$, на порядок меньше канавок, глубина которых $\approx(3.6 \pm 0.1)$ и $\approx(1.0 \pm 0.1) \mathrm{nm}$ (таблица).

\section{4. Спектры PL поверхности кремния}

Спектры PL поверхности кремния показаны на рис. $4, a, b$. В них наблюдаются 4 полосы: 1.62, 1.66 и 1.68 и $2.26 \mathrm{eV}$. Известно, что появление полос в области от 1.5 до $2.5 \mathrm{eV}$ вызвано конфайнментом [12,13], т. е. увеличением ширины запрещенной зоны и нарушением закона сохранения импульса, когда кристаллы кремния имеют наноразмеры. Наблюдение четырех полос в спектре PL, показывает, что существует 4 группы кристаллов, различающихся по размерам.

Известно, что положение максимума полос в спектрах PL зависит от размера нанокристаллов. В литератуpe [12] приведены зависимости энергии максимума полос и от размера нанокристаллов, имеющих вид шаров. Она была использована для оценки размеров нанокристаллов на исследуемой поверхности - $\approx 2 \approx 2.3 \approx 3$ и $\approx 4 \mathrm{~nm}$ (таблица).

Рис. 4. Спектр PL поверхности (100) кремния. 
Размеры „зародышевых“ трещин

\begin{tabular}{l|l|l|c|c|c}
\hline \multicolumn{1}{c|}{ Измеряемый параметр } & \multicolumn{1}{|c}{ Метод определения размера } & \multicolumn{3}{|c}{ Размеры, nm } \\
\hline Глубина канавок & Интерференционный профилометр & 1 & 2.6 & 3.6 & 4.5 \\
\hline Размеры нанокристаллов & Спектр PL & 2 & 2.3 & 3 & 4 \\
\hline Размеры „зародышевых“ трещин & Скорость и время роста максимумов FL & 1.9 & 3 & 3.2 & 6
\end{tabular}

Видно, что полученные значения совпали с глубиной „бороздок“ на поверхности кремния. Вероятно, нанокристаллы расположены на краях таких „бороздок“.

\section{5. Динамика образования „зародышевых“ трещин}

Как уже упоминалось, ранее [7-10] было найдено, что при механическом разрушении кристаллов возникают сигналы FL. Их длительность для кремния составляла $\approx 48 \mathrm{~ns}$ (рис. 5). Они содержали по 4 максимума, образовывавшихся друг за другом через $\approx 10-20$ ns. Каждый максимум соответствует „зародышевой“ трещине [7-10]. Оценим их размеры. Удобнее всего это сделать для первого максимума во временных зависимостях FL при ударе по бойку, установленному на поверхности кремния. Предположим, что скорость роста его интенсивности приблизительно равна средней скорости внедрения бойка в кремний. В наших опытах по бойку ударяли грузом массой $50 \mathrm{~g}$, падающем с высоты $5 \mathrm{~cm}$. Средняя скорость внедрения бойка в этих условиях $\approx 0.5 \mathrm{~m} / \mathrm{s}$. Время роста первого максимума $t_{C} \approx 12 \mathrm{~ns}$ (рис. 5). За это время трещина вырастает на $0.5-12 \approx 6 \mathrm{~nm}$. Интенсивность четвертого максимума в 1.6 раз меньше первого. Поэтому он соответствует трещинам, размер которых $\approx 3.8 \mathrm{~nm}$. Интенсивность 2 и 3 максимумов

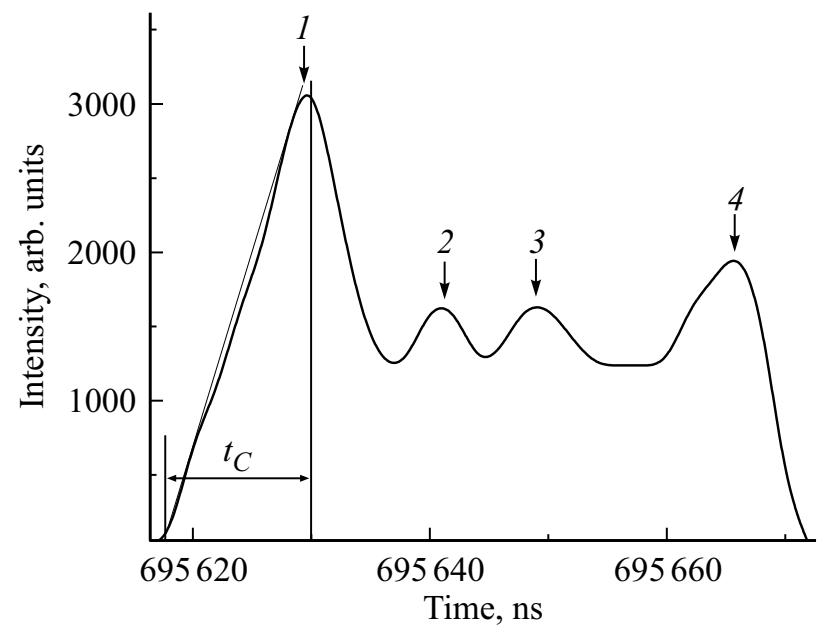

Рис. 5. Сигнал FL при ударе по бойку, установленном на поверхности кремния (100). Стрелками показаны положения максимумов в сигнале, $t_{C}-$ время роста интенсивности первого максимума. в 1.9 меньше первого и они соответствуют трещинам, размер которых $\approx 3.2 \mathrm{~nm}$ (таблица).

Из рассмотрения таблицы следует, что найденные таким способом значения размера „зародышевых“ трещин совпали с глубинной бороздок и размером нанокристаллов. Это показывает, что предположение о том, что скорость роста максимумов в сигналах FL задана скоростью разрушения при ударе по бойку справедливо.

\section{6. Заключение}

Кристалл кремния обладает гранецентрированной кубической решеткой, и, следовательно, содержит 4 системы плоскостей скольжения дислокаций $(111)$ [12,13]. При их пересечении может образоваться кластер из 4 „зародышевых“ трещин.

Анализ результатов, полученных методами интерференционной профилометрии, показал, что размеры глубины бороздок на поверхности кремния имеет 4 наиболее вероятных значения. Размеры нанокристаллов, оцененные по положению максимума полос в спектрах PL и по скорости нарастания максимумов в сигналах FL, тоже имеют 4 значения. Значения размеров глубины бороздок, нанокристаллов и „зародышевых“ трещин совпали (таблица). Это позволяет предположить, что бороздки на поверхности кремния являются „зародышевыми“ трещинами, которые образовались после прорыва барьеров в местах пересечения плоскостей скольжения. В таком случае зародышевые трещины имеют длину берегов в направлении, перпендикулярном росту - 10-30 $\mu \mathrm{m}$, а параллельном росту - несколько $\mathrm{nm}$. Берега трещин состоят из нанокристаллов.

\section{Конфликт интересов}

Авторы заявляют, что у них нет конфликта интересов.

\section{Список литературы}

[1] П.Г. Черемской, В.В. Слезов, В.И. Бетехтин. Поры в твердом теле. Энергоатомиздат, М. (1990). 376 с.

[2] В.И. Бетехтин, А.Г. Кадомцев. ФТТ 47, 5, 801 (2005).

[3] В.Р. Регель, А.И. Слуцкер, Э.Е. Томашевский. Кинетическая природа прочности твердых тел. Наука, М. (1974). $560 \mathrm{c}$.

[4] В.А. Петров, А.Я. Башкарев, В.И. Веттегрень. Физические основы прогнозирования долговечности конструкционных материалов. Политехника, СПб (1993). 475 с. 
[5] А.Н. Орлов. Введение в теорию дефектов в кристаллах. Высш. шк., М. (1983). 144 с.

[6] В.И. Владимиров. Физическая природа разрушения металлов. Металлургия, М. (1984). 280 с.

[7] В.И. Веттегрень, Р.И. Мамалимов, И.П. Щербаков, В.Б. Кулик. ФТТ 62, 1070. (2020).

DOI: $10.21883 / F T T .2020 .07 .49475 .041$

[8] В.И. Веттегрень, А.В. Пономарев, Р.И. Мамалимов, И.П. Щербаков. Физика Земли 6, 106 (2020).

DOI: $10.31857 / \mathrm{S} 0002333720060125$.

[9] В.И. Веттегрень, А.В. Пономарев, В.Б. Кулик, Р.И. Мамалимов, И.П. Щербаков. Геофизические исследования 21, 4, 35 (2020). https://doi.org/10.21455/gr2020.4-3.

[10] В.И. Веттегрень, А.Г. Кадомцев, И.П. Щербаков, Р.И. Мамалимов. ФТТ 63, 1120 (2021).

DOI: $10.21883 /$ FTT.2021.08.51165.060

[11] A.V. Shuldiner, V.A. Zakrevskii. Rad. Protect. Dosimetry. 65, 1-4, 113 (1996).

[12] O. Bisi, S. Ossicini, L. Pavesi. Surface Sci. Rep. 38, 1 (2000).

[13] P.M. Fauchet, J. von Behren. Phys. Status Solidi B 204, R7 (1997).

Редактор Д.В. Жуманов 